\title{
HIV-specific cytotoxic T lymphocytes traffic to lymph nodes and localize at sites of HIV replication and cell death
}

\author{
Scott J. Brodie, ${ }^{1}$ Bruce K. Patterson, ${ }^{2}$ Deborah A. Lewinsohn, ${ }^{3,4}$ Kurt Diem, ${ }^{1}$ \\ David Spach, ${ }^{3}$ Phillip D. Greenberg, ${ }^{3,4,5}$ Stanley R. Riddell, ${ }^{3,4}$ and Lawrence Corey ${ }^{1,3,6}$
}

\begin{abstract}
${ }^{1}$ Department of Laboratory Medicine, University of Washington, Seattle, Washington, USA
${ }^{2}$ Department of Obstetrics and Gynecology, Northwestern University Medical School, Chicago, Illinois, USA

${ }^{3}$ Department of Medicine, University of Washington, Seattle, Washington, USA

${ }^{4}$ Program in Immunology, Fred Hutchinson Cancer Research Center, Seattle, Washington, USA

${ }^{5}$ Department of Immunology, University of Washington, Seattle, Washington, USA

${ }^{6}$ Program in Infectious Diseases, Fred Hutchinson Cancer Research Center, Seattle, Washington, USA
\end{abstract}

Address correspondence to: Scott Brodie, Department of Laboratory Medicine, Vaccine/Virology Division, Room T293X, University of Washington, Seattle, Washington 98195, USA. Phone: (206) 685-6894; Fax: (206) 685-3639;

E-mail: sjbrodie@u.washington.edu.

Received for publication October 18, 1999, and accepted in revised form April 4, 2000.

\begin{abstract}
We have tracked the in vivo migration and have identified in vivo correlates of cytotoxic T-lymphocyte (CTL) activity in HIV-seropositive subjects infused with autologous gene-marked CD8 ${ }^{+} \mathrm{HIV}$-specific CTL. The number of circulating gene-marked CTL ranged from 1.6 to $3.5 \%$ shortly after infusion to less than $0.5 \% 2$ weeks later. Gene-marked CTL were present in the lymph node at 4.5 - to 11 -fold excess and colocalized within parafollicular regions of the lymph node adjacent to cells expressing HIV tat fusion transcripts, a correlate of virus replication. The CTL clones expressed the CCR5 receptor and localized among HIV-infected cells expressing the ligands MIP- $1 \alpha$ and MIP-1 $\beta$, CC-chemokines produced at sites of virus replication. Aggregates of apoptotic cells and cells expressing granzyme-B localized within these same sites. In contrast, lymph node sections from untreated HIV-seropositive subjects, all with significant viral burden (> 50,000 HIV RNA copies/mL plasma), showed no CC-chemokine expression and exhibited only sporadic and randomly distributed cells expressing granzymes and/or apoptotic cells. These studies show that the infused CTL specifically migrate to sites of HIV replication and retain their antigen-specific cytolytic potential. Moreover, these studies provide a methodology that will facilitate studies of both the magnitude and functional phenotype of Ag-specific $\mathrm{CD}^{+} \mathrm{T}$ cells in vivo.
\end{abstract}

J. Clin. Invest. 105:1407-1417 (2000).

\section{Introduction}

A variety of inferential evidence suggests that cytotoxic T lymphocytes (CTL) can exert substantial anti-HIV activity (1-3), including dramatic reductions in cellfree $(4,5)$ and cell-associated $(6,7)$ virus with corresponding increases in $\mathrm{CD}^{+} \mathrm{T}$ cells $(5,8,9)$. Still, hostmediated immune responses to HIV generally fail to completely control virus replication $(10,11)$. Our previous studies $(7,12)$ have shown that by increasing the number of antigen-specific CTL by adoptive transfer, it is possible to lower viral burden. In a previous study (7), adoptively transferred CTL could be identified at sites of HIV replication in lymph nodes; however, the mechanism(s) of the antiviral effects mediated by infused CTL are, as yet, unclear.

Transduction of cells with replication-defective retroviral vectors that encode for antibiotic selection markers, but lack coding sequences for retroviral antigens, has been used extensively as a means to monitor the efficiency of gene transfer (13-16). It is critical in studies in which gene-modified cells are administered to patients to evaluate the quantity and persistence of cells in vivo and to define their distribution and function within tissues. In studies of T-cell therapy, this is of special concern because transferred cells may undergo activationinduced death in vivo (17) or immune elimination of gene-marked cells may occur, especially following repeated infusions (18). The development of accurate, reproducible methods to quantify gene-marked cells in peripheral blood and tissue are central to defining the long-term persistence and function of such cells.

In this paper, we compare two novel methods to quantify and track the in vivo migration and persistence of adoptively transferred HIV-specific CD $8^{+}$CTL bearing a single copy of the neomycin phosphotransferase gene (neo), a commonly used marker for gene transfer studies. We show that gene-marked cells retain their ability to traffic to specific lymph node sites and express cytolytic effector molecules at local sites of HIV replication.

\section{Methods}

Experimental design. The persistence and migration of adoptively transferred gene-modified HIV-specific CTL was studied previously in three of the five subjects in 
this report (7). Herein, we add two new subjects and use newly developed quantitative measures for genemarked $T$ cells and for cells harboring replication-competent HIV. Moreover, we examine for the first time histologic sections of lymph node for sites of CTL localization in the context of granzyme-B expression, apoptosis, and HIV replication.

The clinical protocol was approved by the Fred Hutchinson Cancer Research Center Institutional Review Board, the Recombinant DNA Advisory Committee, and the US Food and Drug Administration. HIV gag-specific CD8 ${ }^{+}$CTL clones were derived from five HIV-seropositive individuals with $\mathrm{CD}^{+} \mathrm{T}$ cell counts between 200 and 500 cells $/ \mathrm{mm}^{3}$ on a stable regimen of anti-retroviral drugs and without evidence of opportunistic infection for at least 4 weeks before entry to the study. The CTL clones were MHC class I restricted and recognized epitopes in either the $\mathrm{p} 17$ or p24 subunit of HIV gag (Table 1). The cloned cells have been characterized for HIV-specific CTL activity (7) and cell surface phenotypes $\left(\mathrm{CD}^{+}, \mathrm{CD}^{-}, \mathrm{CD}^{+}\right.$, and $\mathrm{CCR}^{+}$), including selected cellular adhesins $\left(\mathrm{VLA}-4^{+}, \mathrm{LFA}-1 \alpha^{+}\right.$, and LFA-1 $\left.\beta^{+}\right)(7,19)$. Although these clones expressed many of the surface ligands important in cell trafficking, it is not known which adhesion pathway(s) were actually employed. The clones could also be induced to express the activation antigens CD25 and CD69 and expressed low-levels of granzyme-B before their infusion. Because the clones were selected in G418 media, all contained the neo transgene (7). Two infusions of neo-modified CTL were given at 1-week intervals in doses of approximately $10^{9}$ cells $/ \mathrm{m}^{2}$ and approximately $3.3 \times 10^{9}$ cells $/ \mathrm{m}^{2}$, and a inguinal lymph node was biopsied 4 days after the final infusion.

Peripheral blood was collected daily for the first week after infusions and at biweekly intervals for the next 6 months. Mononuclear cells were isolated from discontinuous density gradients, and absolute CD4 ${ }^{+} \mathrm{T}$-cell and $\mathrm{CD}^{+} \mathrm{T}$-cell counts were determined for each sample collected. Lymph node leukocytes were obtained by forcing tissues through an 80- $\mu \mathrm{M}$ wire mesh (7).

Retroviral vectors. The $\mathrm{LN}$ retroviral vector containing the neomycin phosphotransferase gene (20) was kindly provided by Targeted Genetics Corporation, Seattle, Washington, USA. The virus was produced in the PA317 packaging line and used as supernatant virus for transducing $\mathrm{CD}^{+} \mathrm{T}$ cells. The transduced cells were cloned and selected on G418 media as described (7), and all infused cells contained a single copy of the neo gene.

Limiting dilution PCR: resolution of first-round PCR products by ${ }^{32} P$ liquid bybridization. A semiquantitative solution-phase PCR and liquid hybridization strategy was used to detect neo DNA in purified preparations of PBMC and lymph node mononuclear cells from the first three consecutively enrolled patients. The procedure used neo-specific primer pairs (forward, 5'CGTTGTCACTGAAGCGGGAAGG; reverse, 5'-GGTAGCCGGATCAAGCGTATGC) and a ${ }^{32}$ P-labeled probe (5'-TGGCTG CTATTGGGCGAAGTGC) that hybridized internal to the primer binding sites (Genbank accession number M28245, positions 1901-2045 [primers] and 1926-1947 [probe] of the vector). This assay was capable of detecting one copy of neo plasmid DNA in spiked test samples and as few as five copies of neo DNA in clinical samples. DNA extraction and conditions of the PCR and liquid hybridization procedure have been described previously (7). Assay controls are indicated in the legend of Figure 1.

Limiting dilution PCR: nested PCR. Nested PCR used the same sample preparation and fourfold dilution scheme used for liquid hybridization PCR (Figure 1). Neo-specific outer primers (forward, 5'-GGGTGGAGAGGCTATTCGGCTATGACTGGGCACAACAGACAATCGGCTG; reverse, 5'-GGCGATGCGCTGCGAATCGGGAGCGGCGATACCGTAA) amplified a 724-bp product and inner primers (forward, GGTCACGACGAGATCCTCGCCGTCGGGCATGCGCGCCTT; reverse, GGTGCCCTGAAT-

Table 1

Patient profiles and specificity of adoptively transferred neo-modified HIV gag-specific CD8 ${ }^{+} \mathrm{CTL}$ clones

\begin{tabular}{|c|c|c|c|c|c|c|c|c|c|}
\hline \multirow[t]{2}{*}{$\mathrm{Pt}$} & \multirow[t]{2}{*}{$\begin{array}{l}\text { Antiretroviral } \\
\text { therapy }\end{array}$} & \multirow{2}{*}{$\begin{array}{l}\text { CD4/CD8 ratio } \\
\left.\text { (cells/mm } / \mathrm{mm}^{3}\right)\end{array}$} & \multirow{2}{*}{$\begin{array}{c}\text { Plasma } \\
\text { gag RNA } \\
\text { (copies } \times 10^{3} / \mathrm{mL} \text { ) }\end{array}$} & \multirow{2}{*}{$\begin{array}{l}\text { CTL } \\
\text { clone } \\
\text { L) }\end{array}$} & \multicolumn{2}{|c|}{$\begin{array}{l}\text { CTL dose } \\
\text { (total cells) }\end{array}$} & \multirow{2}{*}{$\begin{array}{c}\text { MHC } \\
\text { restricting } \\
\text { allele }\end{array}$} & \multirow{2}{*}{$\begin{array}{c}\text { gag } \\
\text { protein }\end{array}$} & \multirow[t]{2}{*}{ HIV gag epitope } \\
\hline & & & & & $\begin{array}{l}\text { Infusion } \\
\quad 1\end{array}$ & $\begin{array}{l}\text { Infusion } \\
2\end{array}$ & & & \\
\hline 1 & ZDV, 3TC & $259 / 2063$ & $5.9 \pm 0.8$ & $\begin{array}{l}\text { LN-2A3-5 } \\
\text { LN-21D12-72 } \\
\text { LN-32E4-99 }\end{array}$ & $\begin{array}{l}8 \times 10^{8} \\
6 \times 10^{8} \\
5 \times 10^{8}\end{array}$ & $\begin{array}{l}2.2 \times 10^{9} \\
1.8 \times 10^{9} \\
1.5 \times 10^{9}\end{array}$ & B44 & p24 & AEQASQEVKNW: a.a. 306-316 \\
\hline 2 & 3TC, RIT & $224 / 421$ & $206.1 \pm 38.0$ & $\begin{array}{l}\text { LN-33D7-797 } \\
\text { LN-34H10-827 } \\
\text { LN-36C10-627 }\end{array}$ & $\begin{array}{c}8.1 \times 10^{8} \\
0 \\
1 \times 10^{9}\end{array}$ & $\begin{array}{l}1.2 \times 10^{9} \\
1.1 \times 10^{9} \\
1.2 \times 10^{9}\end{array}$ & $\begin{array}{l}\text { B57 } \\
\text { B57 } \\
\text { B57 }\end{array}$ & p24 & NAWVKVVEEKAFSPEVIPMF: a.a. 153-172 \\
\hline & $\begin{array}{l}\text { d4T, IND, ddI } \\
\text { ddl, NEV, RIT, SQV }\end{array}$ & $\begin{array}{r}261 / 765 \\
\vee \quad 430 / 886\end{array}$ & $\begin{array}{l}<0.02 \\
<0.02\end{array}$ & $\begin{array}{l}\text { LN-9E12 } \\
\text { LN-48D1 }\end{array}$ & $\begin{array}{c}2 \times 10^{9} \\
2.3 \times 10^{9}\end{array}$ & $\begin{array}{c}6 \times 10^{9} \\
4.7 \times 10^{9}\end{array}$ & $\begin{array}{l}\text { A3 } \\
\text { B7 }\end{array}$ & $\begin{array}{l}\text { p17 } \\
\text { p24 }\end{array}$ & $\begin{array}{l}\text { KIRLRPGGK: a.a. 18-26 } \\
\text { SPRTLNAW } \text { a.a. } 148-156\end{array}$ \\
\hline & $3 T C$, ddI, IND & $406 / 526$ & $<0.02$ & $\mathrm{LN}-18 \mathrm{H} 3$ & $2.2 \times 10^{9}$ & $6.7 \times 10^{9}$ & B62 & p17 & RLRPGGKKKY a.a. 20-29 \\
\hline
\end{tabular}

Patients were enrolled in FHCRC Protocol 827. Antiretrovirals listed refer to the stable drug regime at the time of immunotherapy. CD4 ${ }^{+}$and $\mathrm{CD}^{+} \mathrm{T}_{\text {-cell }}$ counts were performed before therapy. Plasma HIV RNA levels were measured by RT-PCR (Amplicor; Roche Diagnostic Systems, Branchburg, New Jersey, USA), and results are shown for the day preceding the first CTL infusion. Epitope specificities of HIV-specific CD8 $8^{+} C T L$ clones are shown for $L N$-transduced (neo ${ }^{+}$) clones. Each clone was restricted by the single MHC class I allele shown and recognized the peptide sequence indicated. Underlined sequence indicates minimal epitope mapped. ZDV, zidovudine; 3TC, lamivudine; RIT, ritonavir; d4T, stavudine; IND, indinavir; ddI, didanosine; SQV, saquinavir; NEV, nevirapine. 
GAACTGCAGGACGAGGCAGCG) produced a 401-bp product (Genbank accession number M28245, positions 1699-2420 [outer] and 1818-2216 [inner] of the vector). This assay was capable of detecting five copies or fewer of neo plasmid DNA and between five and 10 copies of neo DNA in clinical samples. Cycling parameters for both first- and second-round PCR were as follows: three cycles at $94^{\circ} \mathrm{C}$ for 1 minute, $55^{\circ} \mathrm{C}$ for 1 minute, and $72^{\circ} \mathrm{C}$ for 1 minute, followed by 30 cycles of $95^{\circ} \mathrm{C}$ for 15 seconds, $55^{\circ}$ for 45 seconds, and $72^{\circ}$ for 1 minute, and then concluded with a $72^{\circ} \mathrm{C}$ extension for 10 minutes. Two microliters of first-round product was added to the second-round reaction. Second-round PCR products were stained with ethidium bromide and then visualized on $2 \%$ agarose gels.

Quantitative fluorescent probe PCR (TaqMan). Fluorescent probe PCR measures the accumulation of PCR products in "real time" (reviewed by Heid et al., ref. 21). In brief, DNA was extracted from mononuclear cells as described, quantified by spectrophotometry, and four wells of $1 \mu \mathrm{g} /$ well of high-purity DNA applied to each reaction. The amplification mix and PCR conditions

for a $50-\mu \mathrm{L}$ reaction consisted of: $1 \times$ PCR buffer II; $8 \%$ glycerol; $1.0 \mathrm{U}$ AmpErase (uracil glycosylase; Epicentre Technologies Corp., Madison, Wisconsin, USA); 2.5 U AmpliTaq DNA polymerase (Perkin-Elmer Applied Biosystems, Foster City, California, USA); $4 \mathrm{mM}$ $\mathrm{MgCl}_{2} ; 200 \mu \mathrm{M}$ dATP, dGTP, dCTP, and $400 \mu \mathrm{M}$ dUTP; $30 \mu \mathrm{mol}$ forward (5'-GGATTGCACCGAGGTTCTC) and reverse (5'-AGAGCAGCCGATTGTCTGTT) primers (Genbank accession number M28245, positions $1671-1751$ of the vector [81-bp amplimer]); and $20 \mu \mathrm{mol}$ TaqMan probe (position $1704-1730$ of the vector): 5'-FAM-TGCCCAGTCATAGCCGAATAGCCCCATTAMRA-3' (Synthegen, Houston, Texas, USA), where FAM is 6-carboxy fluorescein (emission $=518 \mathrm{~nm}$ ) and TAMRA is 6-carboxy tetramethyl rhodamine (emission $=582 \mathrm{~nm}$ ). Reaction volumes were adjusted to $50 \mu \mathrm{L}$ and transferred to a microtiter plate. To determine the concentration of neo in test samples, $\beta$-actin was used as an internal standard on an identical set of samples. The procedure used $\beta$-actin-specific primers and fluorogenic probe, as provided by the manufacturer (Perkin-Elmer Applied Biosystems). Target and inter-

a

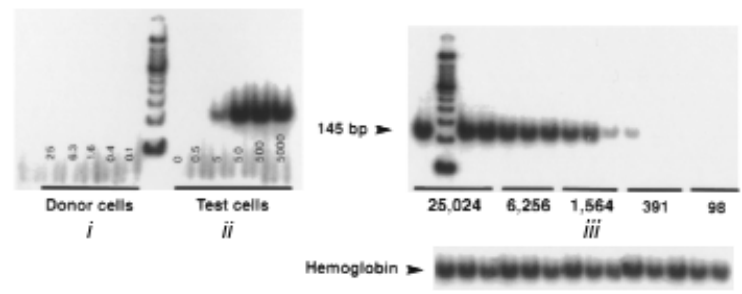

b

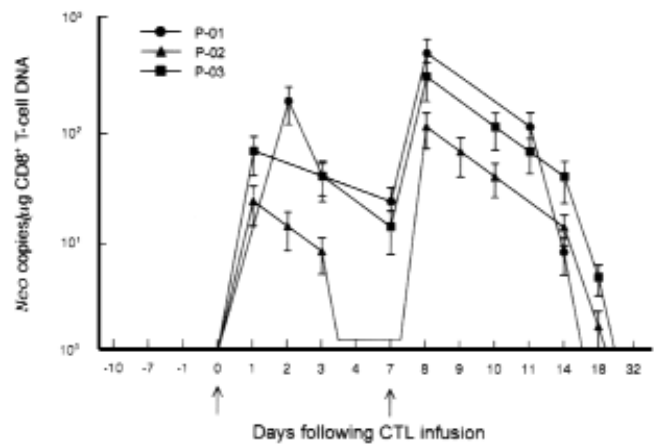
cells) per microgram of PBMC DNA. Independent determinations of the frequency of neo-modified cells varied up to $0.5 \mathrm{log}$. (iii) Serial dilutions of PBMC from a patient who received the second infusion of neo-modified T cells $\left(3.3 \times 10^{9}\right.$ cells $\left./ \mathrm{m}^{2}\right) 24$ hours earlier (patient 1). Endpoint dilution analysis indicates a titer of 2,558 infused neo-positive cells/106 PBMC ( 1 in 391 PBMC). Negative controls consisted of DNA extracted from PBMC before CTL infusions. All samples were positive for the $\beta$-hemoglobin gene. (b) Using a single-round PCR and liquid hybridization strategy, the in vivo persistence of neo-marked $T$ cells was assessed in peripheral blood collected before, during, and after adoptive transfer. The absolute number of $\mathrm{CD} 8^{+} \mathrm{T}$ cells in PBMC was determined by flow cytometry for each time point. Data points indicate mean \pm SEM and represent the number of neo copies per microgram of CD8 $8^{+}$T-cell DNA. Arrows indicate the day of neomarked T-cell infusions. All samples were run in triplicate, and all assays were repeated at least twice. (c) Comparison of PCR/liquid hybridization strategy (described above) with nested PCR in clinical samples, as described in Methods.
C

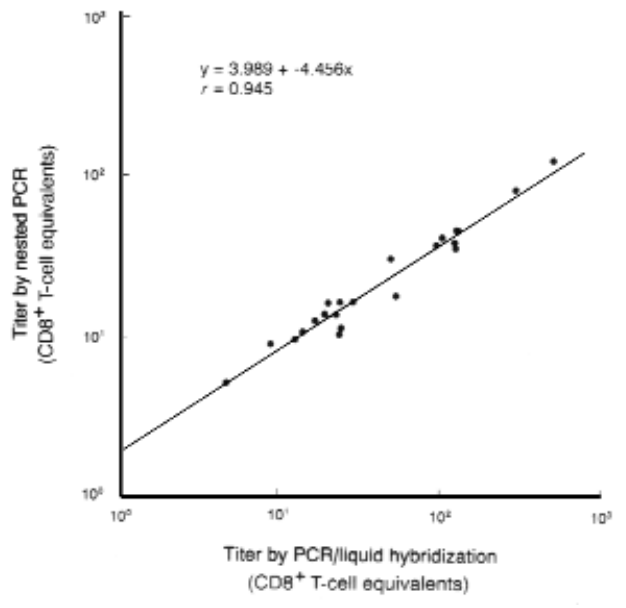


nal control DNA were subjected to $50^{\circ} \mathrm{C}$ for 2 minutes and $95^{\circ} \mathrm{C}$ for 10 minutes, followed by 42 cycles of amplification at $95^{\circ} \mathrm{C}$ for 20 seconds and $60^{\circ} \mathrm{C}$ for 1 minute, using ABI PRISM 7700 sequence detector (Perkin-Elmer Applied Biosystems). All samples were run in triplicate, and all samples were repeated on at least two separate runs. Positive and negative controls consisted of neo-transduced and non-transduced CD8 ${ }^{+}$ T-cell clones, respectively. Because each genome contained no more than one neo gene copy, the frequency of neo-transduced cells was derived by determining the concentration of input DNA and the percentage of $\mathrm{CD}^{+} \mathrm{T}$ cells in the sample.

Single-cell PCR in situ bybridization. Mononuclear cells $\left(2 \times 10^{7} / \mathrm{mL}\right)$ were reacted with $20 \mu \mathrm{g} / \mathrm{mL}$ biotinylated anti-CD8 mAb's (clone B9.11; Coulter-Immunotech, Westbrook, Maine, USA), fixed, and permeabilized in Permeafix $\left(50 \mu \mathrm{L} / 10^{7}\right.$ cells, Ortho Diagnostics, Raritan, New Jersey, USA). It was essential that the Fc portion of the anti-CD8 $\mathrm{mAb}$ be protected from the heat of PCR by conjugation to biotin $(7,22)$. PCR amplification of the neo transgene was performed while in suspension, as described previously (7). Following amplification, the cells were washed and reacted with $100 \mathrm{ng}$ of a neospecific oligonucleotide probe labeled with $5^{\prime}$ and $3^{\prime} 5$ carboxyfluorescein (5'-FAM-AGCATCAGGGGCTCGCGFAM-3', nucleotides 2137-2153 of the vector; Research Genetics, Huntsville, Alabama, USA). The cells were then incubated with $200 \mu \mathrm{g} / \mathrm{mL}$ streptavidin-phycoerythrin (PE; Coulter-Immunotech) and analyzed by two-color flow cytometry. Although as many as $10 \%$ of the total cells were lost during this procedure, there was no selective loss or retention of the neo-transduced cells. At least 5,000 events were counted for each sample. The percentage of dual-positive cells was determined by integration over a range of $0.2 \%$ positive counts on the identically treated negative sample (nontransduced $\mathrm{CD}^{+} \mathrm{T}$ cells). The conditions of the PCR and in situ hybridization procedures, including assay controls, were as described previously (7).

In situ analysis of spliced and unspliced HIV mRNA using RT-PCR in situ bybridization. A highly sensitive RT-PCR in situ hybridization (RT-PCR-ISH) technique was developed to identify tat fusion transcripts indicative of a posttranscriptional splicing event and a putative marker of HIV replication in tissue. The technique was
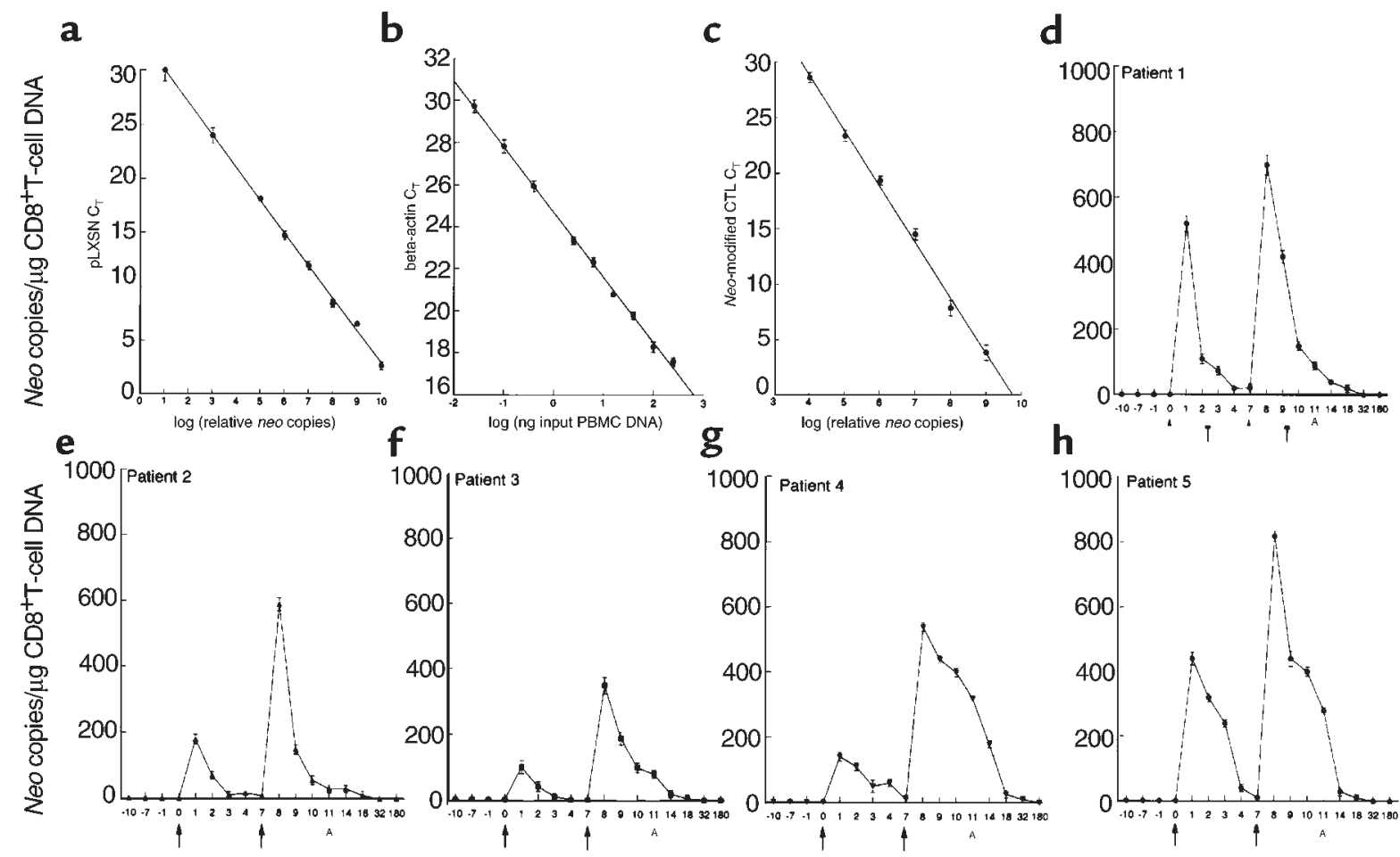

Days after CTL infusion

\section{Figure 2}

Analysis of PBMC for the in vivo persistence of neo-transduced CD8 ${ }^{+}$gag-specific T cells by TaqMan PCR. ( $\mathbf{a}$ and $\mathbf{b}$ ) Standard curves of neo and $\beta$-actin, respectively. Neo plasmid DNA (a) and genomic (PBMC) DNA (b) were diluted serially 1:5 before amplification with the appropriate primer sets. The $\beta$-actin standard curve was used to normalize the results obtained from patient PBMC to $1 \mu \mathrm{g}$ of genomic DNA. (c) Serial 10-fold titration of neo-positive clones starting with an input ratio of 1 part neo DNA to 9 parts genomic DNA. Controls (a-c) illustrate the linearity, sensitivity, and reproducibility of TaqMan PCR. (d-h) The amount of neo present in recovered patient PBMC before, during, and after CTL infusions per microgram of CD8 ${ }^{+} \mathrm{T}$-cell DNA. Parts $\mathbf{d}-\mathbf{h}$ represent patients $1-5$, respectively. All figures show DNA concentration of the samples plotted verses threshold cycle $\left(C_{T}\right)$, and all time points represent the mean \pm SEM of triplicate PCR amplifications. This assay is highly quantitative and capable of detecting $\leq 2$ neo copies per 1 $\mu \mathrm{g}$ of PBMC DNA. Independent determinations of the frequency of neo-marked CD8 ${ }^{+}$cells in PBMC varied $\leq 0.2$ log. Arrows indicate the day of T-cell infusions. ${ }^{A}$ An inguinal lymph node biopsy. All assays were repeated at least twice. Error bars are shown (some are not visible). 


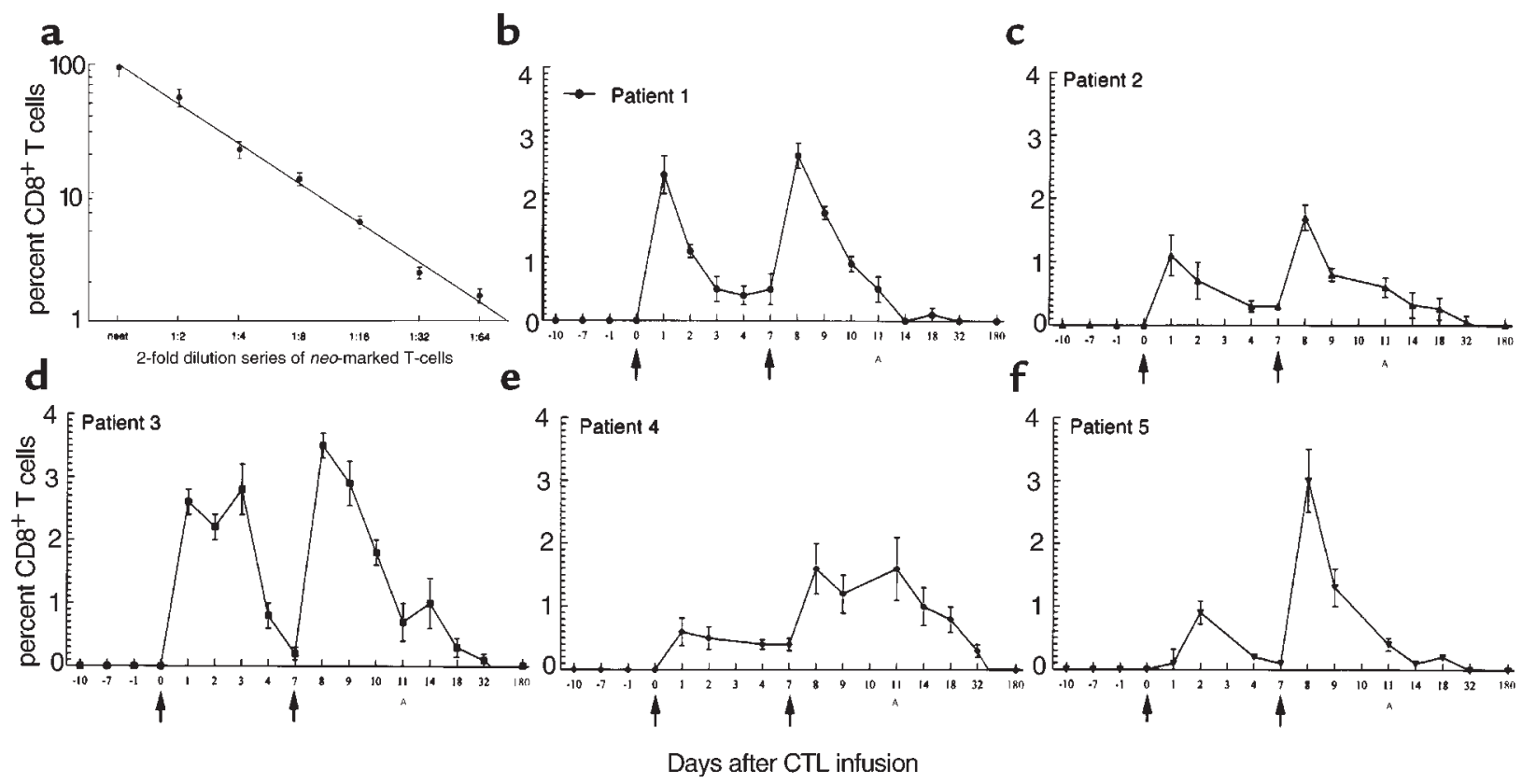

Figure 3

Analysis of PBMC for the in vivo persistence of neo-transduced CD8 $8^{+}$T cells by PCR-ISH and two-color flow cytometry. PBMC from five patients (b-f) were assessed for neo before, during, and after adoptive transfer of neo-transduced T cells. This assay was capable of identifying individual neomodified cells. Independent determinations of the frequency of neo-marked CD8 ${ }^{+}$cells in PBMC varied up to $0.2 \%$. Results represent mean \pm SEM of samples run in triplicate. Arrows indicate the day of T-cell infusions. ${ }^{A}$ An inguinal lymph node biopsy. All assays were repeated at least twice.

similar to what we have described for other RNA viruses $(23,24)$. Briefly, histologic sections were treated with RNase-free DNase-1 (Roche Molecular Biochemicals, Indianapolis, Indiana, USA) and then reacted with reverse transcriptase following the manufacturer's recommendations (RT-PCR kit; Perkin-Elmer Applied Biosystems). The PCR used HIV tat-specific primers MF5869 (5'-GCGAATTCATGGAKCCAGTAGATCCTAGACTA- $3^{\prime}$ [nucleotide positions 5869-5886]) and MF8760 (GCTCTAGACTATCTGTCCCCTCAGCTACTGCTATGG-3' [nucleotide positions 8760-8733]). Specific amplimers were then detected using DIG-labeled oligoprobes that spanned the 5' tat splice junction (MF5945, 5'-ATTGTAAAAAGTGTT-splice-GCTWTCATTGC- $3^{\prime}$ ). The designation $\mathrm{K}$ refers to the single code letter for $\mathrm{G}$ or $\mathrm{C}$, and $\mathrm{W}$ refers to A or $\mathrm{T}$ for degenerative bases (25). Tat plasmids were kindly provided by Manohar Furtado (Northwestern University, Chicago, Illiniois, USA) and have been described previously (25). Digoxigenin-labeled (DIG-labeled) RNA probes were derived as described previously $(7,19)$. PCR and hybridization controls were as described previously $(7,9,19)$.

Laser confocal microscopy. $\mathrm{CD}^{+}$neo-positive, $\mathrm{CD}^{+}$neonegative, and CD8- neo-positive cells were identified by single-cell immunocytochemistry combined with PCRISH. The cells were sorted directly onto silanized glass slides (Perkin-Elmer Applied Biosystems) and analyzed on an ACAS 570 argon laser confocal microscope (Meridian Instruments, Okemos, Michigan, USA) at 488-nm excitation using FITC/PE filter sets. To distinguish intracellular sites of PCR product accumulation, the sorted cells were analyzed by Z-banding, a technique whereby

\section{Figure 4}

Comparison of solution-phase PCR assays for the quantification of neo in lymph node mononuclear cells (filled symbols) and concurrent analysis of PBMC (open circles). Sample preparation, assay procedures, and controls are as described in Methods. For negative controls, lymph node and blood leukocytes were obtained 1 year previously from patient 1 and represent unmodified (neo-negative) CD8 ${ }^{+}$ $T$ cells. Data points denote mean \pm SEM for neo and represent the end-point titer per microgram of $C D 8^{+} \mathrm{T}$-cell DNA. All samples were run in triplicate and all assays repeated at least twice.

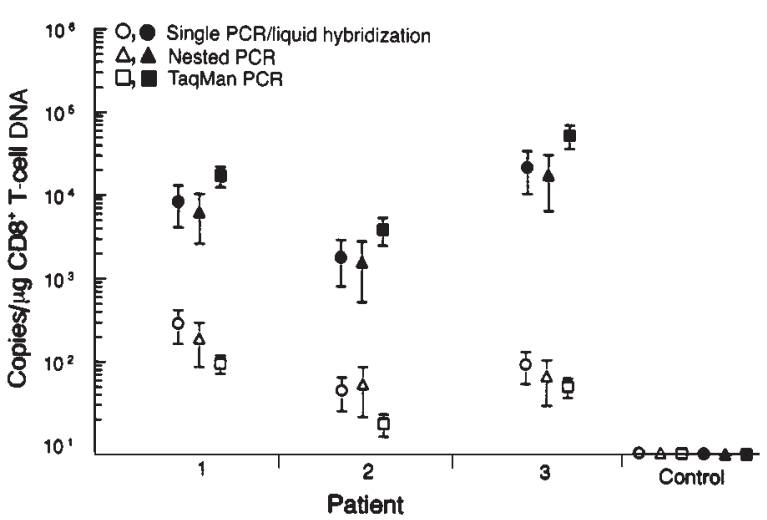


serial $1-\mu \mathrm{m}$ sections could be visualized independently ( $Z$ banding parameters: photomultiplier tube $20.0 \%$, laser power $200 \mathrm{~mW}$, speed $6.00 \mathrm{~mm} / \mathrm{s}, 30$ samples/point).

In vivo correlates of CTL migration and function. PCR-ISH for localization of neo-modified cells in lymph node sections was performed as described previously, including controls (7). Immunostains were also performed following standard procedure $(9,19,26)$, which included an Ag-retrieval step (steaming in $1 \mathrm{mM}$ citrate buffer, pH 6.0, for 20 minutes) and used mAb's (20 $\mu \mathrm{g} / \mathrm{mL}$ ) to the human CD8 (clone C8/144B, IgG ${ }_{1}$;
DAKO Corporation, Carpinteria, California, USA); human CCR5 (clone 45531.111, IgG2b; Endogen Inc., Woburn, Massachusetts, USA); human MIP-1 $\alpha$ (clone 11A3, IgG 2 ; LeukoSite Inc., Cambridge, Massachusetts, USA); human MIP- $1 \beta$ (clone $1 \mathrm{~F} 12, \mathrm{IgG}_{2 \mathrm{~b}}$; LeukoSite Inc.); and granzyme-B (clone B18.1, IgG ; $_{1}$ Alexis Corp., San Diego, California, USA), a serine protease stored in granules of activated CTL. In addition, the TUNEL assay (Oncor Inc., Gaithersburg, Maryland, USA) was used to identify apoptotic cells and is based on terminal deoxynucleotidyl transferase-mediated
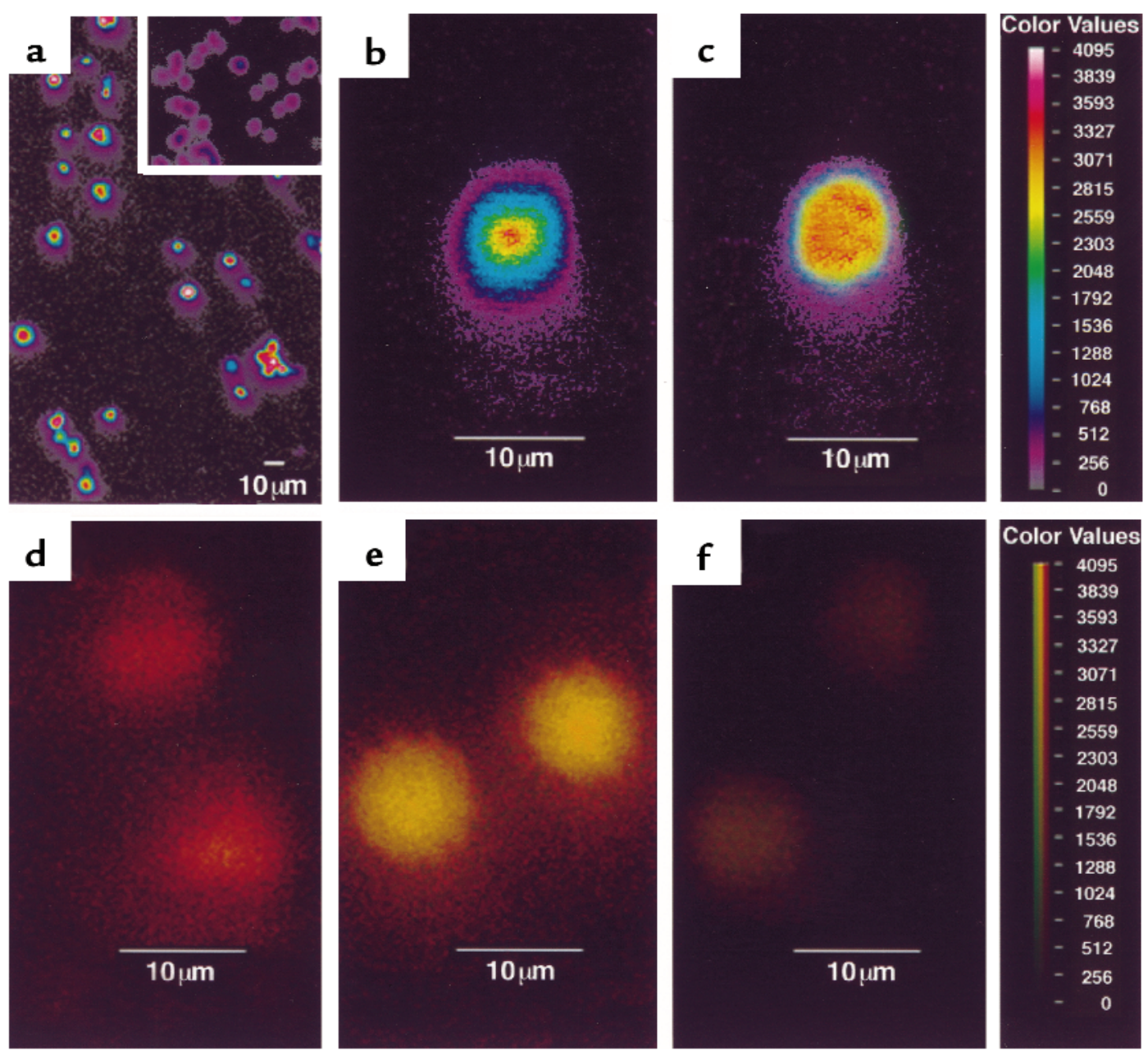

\section{Figure 5}

Visualization of neo-transduced CD8 ${ }^{+} T$ cells by confocal laser microscopy. Cells were prepared as described in Methods and shown in Figure 4. (a) Neo-marked CD8 ${ }^{+}$T-cell clones examined before patient infusions. More than $98 \%$ of the cloned cells stained for CD 8 and neo was detected in more than $95 \%$ of these CD8 $8^{+}$T cells (shown is clone LN-2A3-5 from patient 1 ). Cells containing neo amplimers emit yellow-red fluorescence with a peak fluorescence intensity of 3327. Nontransduced (neo-negative) cells appear purple-blue with a peak fluorescence intensity of 256 (inset). (b) Pictured is a neo-positive cell recovered from a lymph node biopsy taken 4 days after the final T-cell infusion and visualized using the technique of Z-banding. Shown is a 1- $\mu \mathrm{m}$ section taken approximately through the center of a single cell. Note that signal is exclusively intranuclear and has a similar fluorescent intensity to the preinfusion CTL clones (patient 1). (c) For comparison, a similar in situ hybridization procedure, as described previously $(6,7)$, was used to identify cells in lymph node with transcriptionally active HIV. Gag-positive cells emit intense yellow-red fluorescence with intensities ranging from 2,048 to 3,327 (patient 1). However, unlike neo, the signal is found in both the nucleus and cytoplasm, as would be expected with productive infection. (d-f) Dual detection of neo ${ }^{+}$and $\mathrm{CD}^{+} \mathrm{T}$ cells from (d) preinfusion and (e) postinfusion PBMC (patient 5). The CD8 surface antigen was detected using a PE-conjugated antibody and was the only fluorochrome observed (appears red) in preinfusion PBMC samples (d; day 0$)$. In contrast, up to $3 \%$ of PBMCs taken immediately after infusion show both markers and appear yellow (e; day 8 ). Neo was not detected in cells that did not stain with antibodies to CD8 (f). 
(TdT-mediated) dUTP nick-end labeling (TUNEL) of fragmented DNA. The tissues were then reacted with $\mathrm{mAb}$ 's overnight at $4^{\circ} \mathrm{C}$. The remainder of the procedure used an $\mathrm{ABC}$ peroxidase technique with 3,3diaminobenzidine (DAB) as the chromogen (Vector Laboratories, Carpinteria, California, USA). Irrelevant mAb's (IgG $\mathrm{Ig}_{1}$ to the ovine CD4 and CD8 molecules (26) were used as isotype-specific controls, and lymph node sections from both HIV-seronegative (19) and untreated HIV-seropositive (9) individuals were used to evaluate patterns of $\mathrm{CD}^{+}$and $\mathrm{CD}^{+} \mathrm{T}$-cell distribution, granzyme positivity, and extent of apoptosis in normal uninfected tissue and infected but untreated tissue.

Anti-neo CTL responses. PBMC were obtained at various intervals up to 8 weeks after the final neo-marked T-cell infusion. The cells were stimulated with an aliquot of gamma-irradiated autologous neo-transduced T-cell clone as described in Table 1. After two stimulations, aliquots of the cultures were assayed against autologous nontransduced $T$ cells (mock) and neo-transduced T cells at an effector-to-target ratio of 10:1 or 20:1, as described previously (18).

\section{Results}

Persistence of neo-marked cells in peripheral blood. The in vivo persistence of transferred CTL in blood was assessed by detection of neo sequence in samples of DNA extracted from PBMC obtained before, during, and after CTL infusions. Two semiquantitative limiting dilution analyses were compared, liquid hybridization of PCR products to ${ }^{32} \mathrm{P}$-labeled probes and nested PCR (Figure 1). Both assays could detect as few as 5 neo-copies (5 positive cells) per microgram of PBMC DNA (equivalent to $\sim 1.5 \times 10^{5} \mathrm{PBMC}$ ) and produced similar results over a wide range of titers (Figure $1 c ; r$ $=-0.945)$. Analyses of PBMC samples from treated

\section{Figure 6}

Representative histologic sections of inguinal lymph node collected from $\mathrm{p}$ atient 2 by excisional biopsy 4 days after the second infusion of neo-modified HIVspecific CTL. Serial sections were analyzed for sites of localization of neo-modified $\mathrm{CD}^{+} \mathrm{CTL}(\mathrm{PCR}-\mathrm{ISH})(\mathbf{a})$, cells expressing granzyme-B (anti-GrB mAb) (b), cells expressing HIV tat fusion transcripts (RT-PCR-ISH) (c), cells expressing the CC-chemokine MIP-1 $\beta$ (anti-human MIP- $1 \beta \mathrm{mAb})(\mathbf{d})$, and cells showing DNA fragmentation (TUNEL "apoptosis" assay) (e). Dual stains were used to identify the proportion of $\mathrm{CD}^{+}$(anti-CD4 $m A b+T U N E L)(f ;$ inset shows higher magnification of dual-stained cells [arrows]) and $\mathrm{CD}^{+}$(anti-CD8 $\mathrm{mAb}+$ TUNEL) (g) T lymphocytes demonstrating apoptosis. The HIV-specific CTL expressed the cell surface receptors CD8 and CCR5 and could be stimulated to express granzyme-B before their infusion (h: anti-CD8 mAb (left), anti-CCR5 mAb (middle), anti-GrB mAb (right). Antibody labels were detected by immunoperoxidase staining with DAB as the chromogen and apoptotic cells detected by TUNEL, followed by anti-DIG mAb, and developed with BCIP/NBT. f, follicular germinal centers. Bar, $100 \mu \mathrm{m}$.
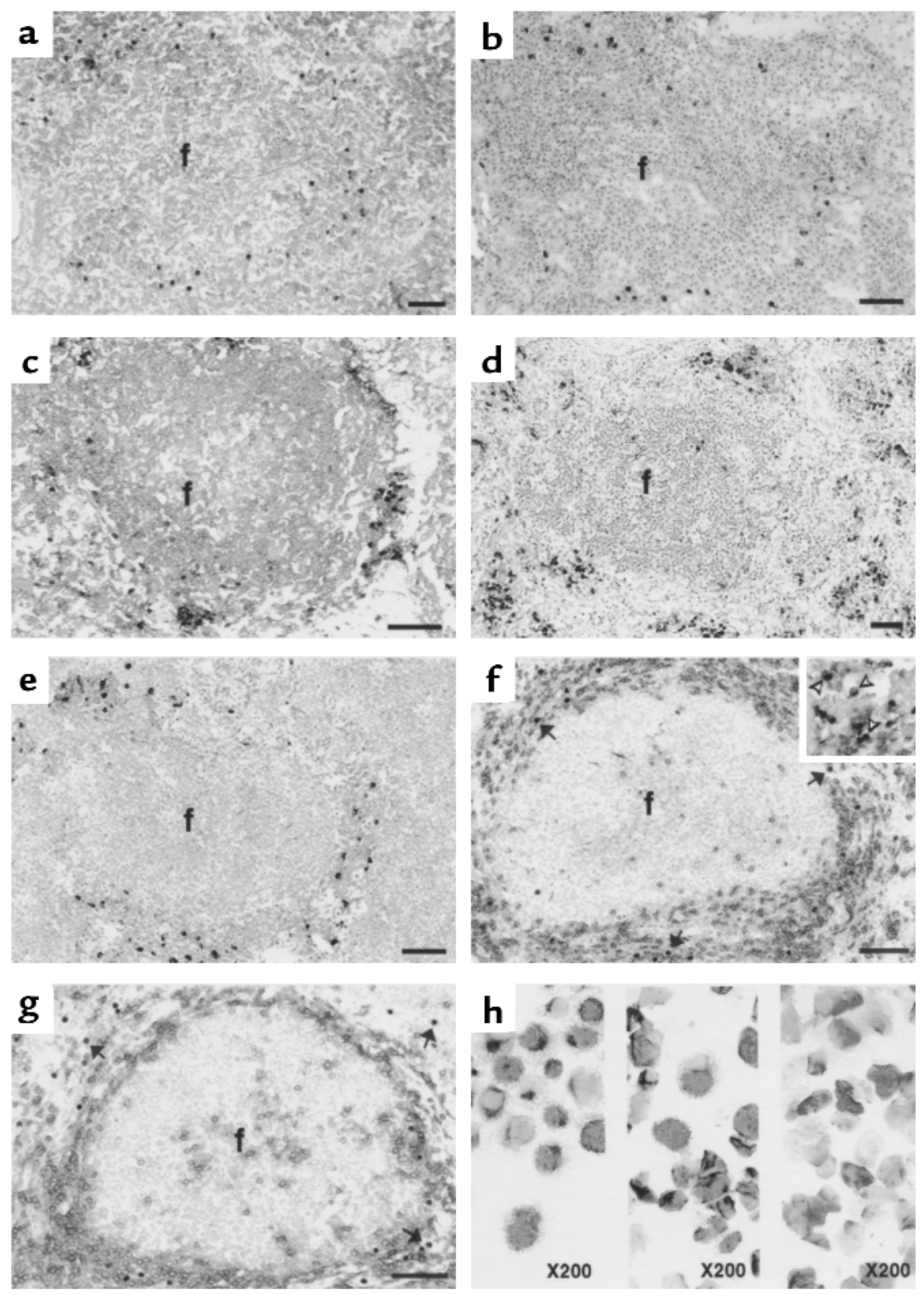
patients using PCR and liquid hybridization revealed a maximal titer of transferred CTL in the blood at 24 to 48 hours after the infusions (Figure $1 \mathrm{~b}$ ). The second infusion consisted of 3.3 times the cell dose given in the first infusion. Infusion of higher numbers of transduced CTL resulted in higher numbers of circulating neo-marked cells. Based on the absolute number of $\mathrm{CD}^{+} \mathrm{T}$ cells in PBMC determined independently for all time points and the assumption that all cells containing neo represented adoptively transferred $\mathrm{CD}^{+} \mathrm{T}$ cells, the data were expressed as neo copies per microgram of $\mathrm{CD}^{+} \mathrm{T}$-cell DNA. In experiments in which $10^{6} \mathrm{PBMC}$ were assayed in triplicate and assays run at least twice, neo was detected in peripheral blood for only 2 to 3 weeks ( $17.4 \pm 3.4$ days) after the final T-cell infusion (Figure 1b).

Because both the liquid hybridization and nested PCR assays are labor intensive and semiquantitative in nature, we reassayed the samples using the fluorescent-based real-time PCR assay (TaqMan). The TaqMan PCR assay produced results comparable to those resulting from limiting dilution analyses. Using TaqMan PCR we detected a single copy of neo plasmid DNA spiked into as much as $1 \mu \mathrm{g}$ of human DNA and as few as 2 neo-transduced cells spiked into $10^{6}$ nontransduced PBMC (Figure 2). Moreover, the data could be reproduced in repeat samples within $0.2 \mathrm{log}$. As shown in Figure 2, all five patients demonstrated consistently higher peak concentrations of adoptively infused cells with the second versus the first infusion. Peak responses ranged from 350 to 820 neo copies $/ \mu \mathrm{g} \mathrm{CD} 8^{+} \mathrm{T}$-cell DNA ( 0.3-0.6\% of $\mathrm{CD}^{+} \mathrm{T}$ cells in PBMC). Neo-marked cells dropped to undetectable concentrations ( $<5$ neo copies/ $\mu$ g DNA) by day 18 after the second infusion. Longer-term follow up revealed only sporadic detection for 4 to 6 weeks after infusion.

Without providing an ancillary cell-purification step, strategies based on solution-phase PCR, including TaqMan, do not distinguish the cell type harboring neo. To evaluate which cells contained the neo transgene, we combined immunocytochemistry with PCR-ISH followed by detection of dual-labeled cells using two-color flow cytometry (7). By this technique, within 24-48 hours of the initial CTL infusion, neo was detected in $0.5 \%-2.7 \%$ of $\mathrm{CD}^{+} \mathrm{T}$ cells in peripheral blood. No neomycin was detected in any other cell type examined in PBMC, including $\mathrm{CD}^{+} \mathrm{T}$ cells, CD $19^{+} \mathrm{B}$ cells, $\mathrm{CD} 1 \mathrm{a}^{+}$dendritic cells, and $\mathrm{CD} 14^{+}$ monocytes. As shown in Figure 3b, 1 day after infusion of the highest CTL dose, neo-marked cells comprised from $1.6 \%$ to $3.5 \%$ of $\mathrm{CD}^{+} \mathrm{T}$ cells in blood. As with the solution-based PCR assays, the frequency of transferred CTL in blood, as measured by in situ PCR, declined gradually after each infusion, and neomarked cells were no longer detected between 1 and 3 weeks (13.8 \pm 7.5 days) after the final T-cell infusion. Although this assay was highly specific and identified the neo transgene only in $\mathrm{CD}^{+} \mathrm{T}$ cells, the lower threshold of detection was $0.2 \%$ (1 in $500 \mathrm{CD}^{+} \mathrm{T}$ cells). Thus, unlike the limiting dilution and TaqMan systems, rare targets were not always detected using the in situ PCR technique. However, because target amplification takes place intracellularly, in situ PCR was extremely efficient when compared with extraction-based PCR methods $(7,22)$. Thus, during peak responses we often observed slightly higher percentages of gene-marked cells using this technique.

Sequestration of neo-marked cells in lymph node. In three patients, an inguinal lymph node was biopsied 4 days after the final infusion to assess the homing of adoptively transferred $\mathrm{T}$ cells to lymph node sites. In a previous study of these three patients, we used in situ PCR and flow cytometry to show that $5,2.2$, and $7.9 \%$ of the $\mathrm{CD}^{+} \mathrm{T}$ cells in the lymph node harbored neo DNA, whereas concurrent analysis of PBMC revealed that only $0.5,0.5$, and $0.7 \%$ of $\mathrm{CD}^{+} \mathrm{T}$ cells were $n e o^{+}(7)$. Thus, neo-modified $\mathrm{CD}^{+}$CTL accumulated in the lymph node in 4.5-11-fold excess of $n e o^{+}$cells in the peripheral blood.

In this study, these findings were corroborated by solution-phase PCRs where there was at least a 2.0 log increase in neo DNA in lymph node cell lysates when compared with PBMC examined concurrently (Figure 4). It is interesting that the TaqMan assay consistently demonstrated slightly higher yields of neo-marked $\mathrm{T}$ cells in lymph node preparations and produced a much tighter SE than either nested or liquid hybridization systems. This is likely related to the more consistent linear range of the assay as compared with endpoint dilution methods using gel-based techniques. Still, results from the three solution-phase PCRs were similar when measuring from the same sample $(P>0.05$, ANOVA). There was also good correlation when comparing results obtained from solution versus suspension-based PCR, particularly when the percentage of neo-positive $\mathrm{CD}^{+} \mathrm{T}$ cells was equal to or greater than $0.5 \%$ above the lower limit of detection. This is likely due to false-positive readings associated with cellular autofluorescence at the lower limits of the assay. For example, 5\% or more of the neo-positive lymph node $\mathrm{CD}^{+} \mathrm{T}$ cells from patient 1 contained the neo amplimer ( 7,500 neo copies/ $\mu \mathrm{g}$ of $\mathrm{CD}^{+}$T-cell DNA), whereas solution-based PCR showed that the same patient had an average of 8,000 neo copies per microgram of $\mathrm{CD}^{+} \mathrm{T}$-cell DNA. Collectively, both suspension-based and solution-based assays clearly demonstrate that the transferred cells effectively trafficked to and preferentially accumulated within lymph nodes.

Neo-marked cells in blood and lymph node are exclusively $C D 8^{+} T$ lymphocytes. In a previous study in which an autologous CD8 ${ }^{+}$HIV-specific CTL clone was adoptively transferred to a single patient, the infused CTL rapidly underwent apoptosis and were cleared from the blood presumably by phagocytosis (17). To determine whether neo DNA detected in our patients remained within transferred $\mathrm{CD}^{+} \mathrm{CTL}$ or was 
engulfed by phagocytes, the same preparations of mononuclear cells examined using PCR-ISH and twocolor flow cytometry were also visualized by two-color laser confocal microscopy (Figure 5). This procedure was sensitive enough to detect equal to or greater than $99 \%$ of preinfusion gene-marked cells (Figure 5a). Interestingly, neo amplimers localized exclusively within the cell nucleus (Figure 5b), which contrasted with a marker for HIV RNA that was detected in both the nucleus and cytoplasm (Figure $5 \mathrm{c}$ ). With this technique, neo DNA was again detected only in CD8+ lymphocytes and only in cells subjected to PCR using neospecific primers and oligonucleotide probes specific for sense-strand product DNA (Figure 5d).

Colocalization of adoptively infused cells in lymph node sites of granzyme- $B$ expression, CC-chemokine expression, $H I V$ replication, and apoptosis. To assess the potential in vivo antiviral activity of the infused CCR5 ${ }^{+} \mathrm{CTL}$, we performed immunohistochemistry on serial sections of lymph node for granzyme-B activity, a measure of activated CTL $(17,27)$, and for CC-chemokines that facilitate CCR5 adhesive interactions in cells expressing HIV (28). Cells staining for granzyme-B (Figure $6 \mathrm{~b})$ showed a remarkably similar pattern of distribution to that of the gene-marked CTL (Figure 6a). Moreover, cells expressing granzyme-B localized adjacent to cells containing HIV tat fusion transcripts (Figure 6c) that were in the same $\mathrm{T}$ cell-dependent sites as cells expressing the CC-chemokines MIP- $1 \alpha$ and MIP-1 $\beta$ (Figure 6d). The same parafollicular region of the lymph node showed high concentrations of apoptotic cells (Figure 6e). Dual staining of apoptotic cells for CD4 (Figure 6f) and CD8 (Figure $6 \mathrm{~g})$ surface antigens showed that DNA fragmentation was slightly more common in $\mathrm{CD}^{+}$cells $(1 \%$ of CD4 and $0.7 \%$ of CD8). All three subjects that consented to lymph node biopsy had similar and substantial viral burden in lymph nodes (7), and all adoptively transferred CTL clones expressed similar levels of CD8, CCR5, and granzyme-B before their infusion (Figure 6h). Because all test subjects had similarly high viral burden, it was not possible to investigate CTL homing or killing as a function of viral load within this cohort.

Induction of neo-specific cytolytic T-cell responses. In both animal and human studies, the persistence of autologous gene-marked cells can be limited by the development of a host immune response to the transgene product $(18,29)$. The five patients receiving neo-modified $\mathrm{CD}^{+} \mathrm{CTL}$ clones in the present study were evaluated for cytolytic T-cell responses to neo. No neo-specific cytolytic activity was detected in cultures of pretreatment PBMC stimulated with gamma-irradiated autologous neo-modified $\mathrm{T}$ cells in any of the five patients. However, neo-specific CTL activity was observed in post-treatment cultures from three of the five patients (patients 2, 3, and 5). This lytic activity was first detected 2 weeks after completing the final $\mathrm{T}$-cell infusion in patient 5 and 4 weeks after the $\mathrm{T}$ - cell infusions in the other two patients. There was no apparent difference in the kinetics with which neomarked CTL declined in patients who developed neospecific CTL compared with those who did not. One patient (patient 4) demonstrated nonspecific lytic activity that was stable over the course of the study and one (patient 1) remained negative in all assays.

\section{Discussion}

An objective of many clinical gene transfer experiments has been to determine whether the transferred gene-modified cells persist, traffic normally, and function in vivo. One major obstacle in defining these issues has been accurate and quantitative detection of low-frequency targets in vivo $(7,13,15,30)$. Detection of rare cells containing specific nucleic acid sequences is often confounded by the low copy number of the target sequence and the difficulty isolating these cells from a heterogeneous population. We demonstrate two different PCR-based approaches; TaqMan chemistry and PCR-ISH, coupled with flow cytometry, can be used to quantify and track the in vivo migration and persistence of adoptively transferred $\mathrm{CD}^{+} \mathrm{T}$ cells bearing a single copy of the neo transgene. The fluorescent probe real-time PCR (TaqMan) assays, when compared with limiting dilution analyses, exhibited increased sensitivity for detection, produced a much narrower intraassay SE, and reproduced repeat determinations within $0.2 \mathrm{log}$. Moreover, TaqMan allowed us to compare the quantitative measurement of gene-marked $\mathrm{T}$ cells by PCR-ISH with an easily manipulated solution-phase PCR technology, enhancing the reproducibility of the results and overcoming some of the specificity concerns that accompany all in situ PCR work $(23,24,31)$.

We show that neo is readily quantified using TaqMan PCR, but, similar to other solution-phase PCR techniques, the product DNA signal is averaged for the number of input cells that are lysed; thereby the association with individual cells is lost. The use of PCR combined with the target localizing capability of ISH has been instrumental in detecting intracellular targets of low copy number $(23,24,31,32)$. Still, a large number of microscopic fields need to be surveyed to demonstrate a rare affected cell. By combining PCR-ISH with flow cytometry, it is possible to objectively evaluate large numbers of cells with the occasional rare target sequence. Moreover, amplification of intracellular target sequences allows for detection sensitivities greater than that of solution-phase PCRs $(7,22)$.

Using PCR-ISH combined with flow cytometry, we have shown previously that the neo-marked $\mathrm{CD}^{+} \mathrm{T}$ cells efficiently home to lymph nodes and accumulate within $T$ cell-dependent areas of the lymph node adjacent to cells expressing HIV gag RNA (7). In this study we provide evidence that a proportion of these virusinfected, transcriptionally-active $\mathrm{T}$ cells contained spliced gene transcripts, a strong correlate of productive virus infection $(25,33)$. Moreover, these virusinfected cells expressed the CC-chemokines MIP- $1 \alpha$ 
and MIP-1 $\beta$, tissue ligands for activated T cells expressing the CCR5 receptor (28). Thus, our current studies demonstrate that adoptively transferred HIV-specific neo-modified CTL retained their ability to traffic, possibly through CCR5/CC-chemokine interactions, and localize to sites of HIV replication.

Antiviral effects have been demonstrated in association with the adoptive transfer of antigen-specific $\operatorname{CTL}(7,12,34-38)$. This reflects, in part, the destruction of virus-infected target cells induced by the release of cytolytic granules containing perforin, which damages the membrane of the target cell, and granzymes, which induce apoptosis. In untreated "control" subjects we studied, all of whom had high levels of viremia and many who had measurable CTL responses (8), only rare and randomly distributed cells expressing granzyme-B and/or cells demonstrating DNA fragmentation were observed. Moreover, there was little association between granzyme$B$ activity and cells replicating HIV in these subjects. These findings are consistent with the recent observations that in $\mathrm{CD}^{+}$-deficient hosts, $\mathrm{CD}^{+}$virus-specific CTL fail to mediate effector functions $(39,40)$. The infusion of activated cytolytic effector cells may overcome this defect. Indeed, in treated subjects granzyme-B-positive cells were detected in a pattern similar to cells harboring neo and adjacent to cells expressing HIV mRNA.

Both our gel-based and TaqMan systems showed that adoptively transferred neo-marked $\mathrm{T}$ cells persisted in the blood for less than 21 days in all five patients studied. Our protocol called for the administration of neo-marked CTL late in the treatment course. Earlier infusions of unmarked $\mathrm{CD}^{+} \mathrm{HIV}$-specific CTL (not shown) increased direct HIV-specific cytolytic activity in fresh PBMC obtained 1 day after infusion, but lytic activity declined to baseline levels within 14 days, suggesting that loss of unmarked $\mathrm{CD}^{+} \mathrm{T}$ cells occurred with similar kinetics to the decline in neo-marked CTL (7). Elimination by an immune response to the transgene product was an alternative explanation for the rapid decline in genemarked T cells detected in peripheral blood (18). CTL responses to neo developed in three of the five patients, but these responses were detected long after the early decline in transferred HIV-specific CTL (7).

In summary, this study extends our previous investigations of adoptive transfer of antigen-specific $\mathrm{CD}^{+} \mathrm{T}$ cells for HIV infection. First, it provides a quantitation of the levels of circulating $\mathrm{CD}^{+} \mathrm{T}$ cells that are achieved by adoptive transfer using a variety of solution and in situ techniques to detect genemarked cells. Second, it confirms the accumulation of transferred T cells in lymph node. Third, it demonstrates by use of a variety of in situ and immunohistochemical techniques the presence of activated "granzyme-positive" CTL in sites of neo gene accumulation and HIV replication, providing evidence for in vivo activity of the infused cells. Fourth, our study provides a potential mechanism of CTL homing to sites of HIV replication in lymph nodes mediated through CCR5/CC-chemokine interactions emanating from inside the lymph node. Collectively, these studies provide the methodology that should facilitate studies of both the magnitude and functional phenotype of Ag-specific $\mathrm{CD}^{+} \mathrm{T}$ cells in vivo.

\section{Acknowledgments}

We thank Corazon de la Rosa, Nancy Wright, Alexis Motoshige, Donna Kelly, Jennifer Joyce, and Eric Peterson for technical assistance; Douglas Ringler (LeukoSite Inc.) for mAb's to MIP- $1 \alpha$ and MIP- $1 \beta$; and Targeted Genetics Corporation for providing the LN retroviral vector. This study was supported by funds from the National Institutes of Health (AI-36613, AI41535, AI-30731, AI-18029).

1. Klein, M.R., et al. 1995. Kinetics of Gag-specific cytotoxic T lymphocyte responses during the clinical course of HIV-1 infection: a longitudinal analysis of rapid progressors and long-term asymptomatics. J. Exp. Med. 181:1365-1372.

2. Schmitz, J.E., et al. 1999. Control of viremia in simian immunodeficiency virus infection by CD8 $8^{+}$lymphocytes. Science. 283:857-860.

3. Lisziewicz, J., et al. 1999. Control of HIV despite the discontinuation of antiretroviral therapy. N. Engl. J. Med. 340:1683-1684.

4. Koup, R.A., et al. 1994. Temporal association of cellular immune responses with the initial control of viremia in primary human immunodeficiency virus type 1 syndrome. J. Virol. 68:4650-4655.

5. Borrow, P., Lewicki, H., Hahn, B.H., Shaw, G.M., and Oldstone, M.B. 1994. Virus-specific CD8+ cytotoxic T-lymphocyte activity associated with control of viremia in primary human immunodeficiency virus type 1 infection. J. Virol. 68:6103-6110.

6. Patterson, B.K., et al. 1999. Monitoring HIV-1 treatment in immunecell subsets with ultrasensitive fluorescence-in-situ hybridisation. Lancet. 353:211-212.

7. Brodie, S.J., et al. 1999. In vivo migration and function of transferred HIV-1-specific cytotoxic T cells. Nat. Med. 5:34-41.

8. Musey, L., et al. 1997. Cytotoxic T cell responses, viral load, and disease progression in early human immunodeficiency virus type 1 infection. N. Engl. J. Med. 337:1267-1274.

9. Berrey, M.M., et al. 2000. Treatment of primary HIV-1 infection with triple combination antiretroviral therapy reduces rapid progression to AIDS. J. Infect. Dis. In press.

10. McMichael, A. 1998. T cell responses and viral escape. Cell. 93:673-676.

11. Rowland-Jones, S.L., et al. 1999. Broadly cross-reactive HIV-specific cytotoxic T-lymphocytes in highly-exposed persistently seronegative donors. Immunol. Lett. 66:9-14.

12. Walter, E.A., et al. 1995. Reconstitution of cellular immunity against $\mathrm{CMV}$ in recipients of allogeneic bone marrow by adoptive transfer of T-cell clones from the donor. N. Engl. J. Med. 333:1038-1044.

13. Kohn, D.B., et al. 1995. Engraftment of gene-modified umbilical cord blood cells in neonates with adenosine deaminase deficiency. Nat. Med. 1:1017-1023.

14. Merrouche, Y., et al. 1995. Clinical application of retroviral gene transfer in oncology: results of a French study with tumor-infiltrating lymphocytes transduced with the gene of resistance to neomycin. J. Clin. Oncol. 13:410-418.

15. Abe, T., et al. 1998. Transduction of retrovirus-mediated NeoR gene into $\mathrm{CD} 34^{+}$cells purified from granulocyte colony-stimulating factor (G-CSF)-mobilized infant and cord blood. Exp. Hematol. 26:185-187.

16. Contassot, E., et al. 1998. Retrovirus-mediated transfer of the herpes simplex type I thymidine kinase gene in alloreactive T lymphocytes. Hum. Gene Ther. 9:73-80.

17. Tan, R., et al. 1999. Rapid death of adoptively transferred T cells in acquired immunodeficiency syndrome. Blood. 93:1506-1510.

18. Riddell, S.R., et al. 1996. T-cell mediated rejection of gene-modified HIV-specific cytotoxic T lymphocytes in HIV-infected patients. Nat. Med. 2:216-223.

19. Brodie, S.J., de la Rosa, C., Howe, G., Travis, W.D., and Diem, K. 1999. Pediatric AIDS-associated lymphocytic interstitial pneumonia and pulmonary arterio-occlusive disease: role of VCAM-1/VLA-4 adhesion pathway and human herpesviruses. Am. J. Pathol. 154:1453-1464.

20. Miller, A.D. 1992. Human gene therapy comes of age. Nature. 
357:455-460

21. Heid, C.A., Stevens, J., Livak, K.J., and William, P.M. 1996. Real time quantitative PCR. Genome Res. 6:986-994.

22. Patterson, B.K., et al. 1993. Detection of HIV-1 DNA and messenger RNA in individual cells by PCR-driven in situ hybridization and flow cytometry. Science. 260:976-979.

23. Brodie, S.J., et al. 1998. Epizootic hemorrhagic disease: analysis of tissues by amplification and in situ hybridization reveals widespread orbivirus infection at low copy numbers. J. Virol. 72:3863-3871.

24. Brodie, S.J., et al. 1998. The effects of pharmacological and lentivirusinduced immune suppression on orbivirus pathogenesis: assessment of virus burden in blood monocytes and tissues by reverse transcription-in situ PCR. J. Virol. 72:5599-5609.

25. Furtado, M.R., Balachandran, R., Gupta, P., and Wolinsky, S.M. 1991. Analysis of alternatively spliced human immunodeficiency virus type1 mRNA species, one of which encodes a novel tat-env fusion protein. Virology. 185:258-270.

26. Brodie, S.J., et al. 1995. Ovine lentivirus expression and disease: virus replication, but not entry, is restricted to macrophages of specific tissues. Am. J. Pathol. 146:1-13.

27. Lewis, D.E., Ng Tang, D.S., Adu-Oppong, A., Schober, W., and Rodgers, J.R. 1994. Anergy and apoptosis in CD8 ${ }^{+} \mathrm{T}$ cells from HIVinfected persons. J. Immunol. 153:412-420.

28. Cyster, J.G. 1999. Chemokines and cell migration in secondary lymphoid organs. Science. 286:2098-2102.

29. Dunbar, C.E., et al. 1995. Retrovirally marked CD34-enriched peripheral blood and bone marrow cells contribute to long-term engraftment after autologous transplantation. Blood. 85:3048-3057.

30. Roskrow, M.A., et al. 1998. Administration of neomycin resistance gene marked EBV specific cytotoxic T-lymphocytes to patients with relapsed EBV-positive Hodgkin disease. Hum. Gene Ther. 9:1237-1250.
31. Embretson, J., et al. 1993. Massive covert infection of helper T lymphocytes and macrophages by HIV during the incubation period of AIDS. Nature. 362:359-362

32. Diamond, C., et al. 1998. Human herpes virus eight in prostate tissue on men with Kaposi's sarcoma. J. Virol. 72:6223-6227.

33. Furtado, M.R., et al. 1999. Persistence of HIV-1 transcription in peripheral blood mononuclear cells in patients receiving potent antiretroviral therapy. N. Engl. J. Med. 340:1614-1622.

34. Heslop, H.E., et al. 1996. Long-term restoration of immunity against Epstein-Barr virus infection by adoptive transfer of gene-modified virus-specific T lymphocytes. Nat. Med. 2:551-555.

35. Terai, C., Kornbluth, R.S., Pauza, C.D., Richman, D.D., and Carson, D.A. 1991. Apoptosis as a mechanism of cell death in cultured T lymphocytes acutely infected with HIV-1. J. Clin. Invest. 87:1710-1715.

36. Oyaizu, N., et al. 1993. Accelerated apoptosis in peripheral blood mononuclear cells (PBMCs) from human immunodeficiency virus type- 1 infected patients and in CD 4 cross-linked PBMCs from normal individuals. Blood. 82:3392-3400.

37. Groux, H., Monte, D., Bourrex, J.M. Capron, A and Ameisen, J.C. 1992. Activation-induced death by apoptosis in CD4 T cells from human immunodeficiency virus-infected asymptomatic individuals. J. Exp. Med. 175:331-340.

38. Finkel, T.H., et al. 1995. Apoptosis occurs predominantly in bystander cells and not in productively infected cells of HIV-and SIV-infected lymph nodes. Nat. Med. 2:129-134.

39. Zajac, A.J., et al. 1998. Viral immune evasion due to persistence of activated T cells without effector function. J. Exp. Med. 188:2205-2213.

40. Spiegel, H.M.L., et al. 2000. Human immunodeficiency virus type-1 and cytomegalovirus-specific cytotoxic $\mathrm{T}$ lymphocytes can persist at high frequency for prolonged periods in the absence of circulating peripheral CD4 ${ }^{+}$T cells. J. Virol. 74:1018-1022. 